\title{
Úng dụng mô hình Mike 11 mô phỏng quá trình lan truyền chất ô nhiễm do nuôi trồng thủy sản trên một số sông lớn tỉnh Quảng Trị
}

\author{
Nguyễn Vũ Anh Tuấn ${ }^{1, *}$, Nguyễn Quang Hưng ${ }^{2}$, \\ Nguyễn Thanh Sơn ${ }^{2}$, Nguyễn Thị Liên ${ }^{2}$ \\ ${ }^{1}$ Tổng cuc Hậu cần - Kỹ thuật, Bộ Công an, 80 Trần Quốc Hoàn, Cầu Giá́y, Hà Nội, Việt Nam \\ ${ }^{2}$ Khoa Khi tuợng Thủy văn và Hải duoong học, Truờng Đại học Khoa học Tụ nhiên, \\ ĐHQGHN, 334 Nguyễn Trãi, Thanh Xuân, Hà Nội, Việt Nam
}

Nhận ngày 08 tháng 8 năm 2016

Chỉnh sửa ngày 26 tháng 8 năm 2016; Chấp nhận đăng ngày 16 tháng 12 năm 2016

\begin{abstract}
Tóm tắt: Bài báo trình bày các kết quả mô phỏng chất lượng nước trên các sông chính của tỉnh Quảng Trị có xét đến tác động của xả thải từ các điểm nuôi trồng thủy sản sử dụng mô hình Mike 11. Số liệu mưa và mực nước năm 2005 và 2009 được sử dụng để xây dựng mổ hình thủy văn và thủy lực. Các số liệu quan trắc chất lượng nước hơn 30 điểm trên hệ thống sông của các năm 2013 và 2014 , số liệu thực đo khảo sát các đơn vị nuôi trồng thủy sản được sử dụng để thiết lập mô hình chất lượng nước, mô phỏng quá trình lan truyền chất ô nhiễm trên sông. Các kết quả mồ phỏng đã được so sánh với các số liệu thực đo để khẳng định độ tin cậy của mô hình và phân tích, làm sáng tỏ hiện trạng chất lượng nước cũng như làm cơ sở để xây dựng công cụ quy hoạch nuôi trồng thủy sản trên khía cạnh bảo vệ môi trường.
\end{abstract}

Tù khóa: Chất lượng nước, nuôi trồng thủy sản, Mike 11 WQ, Quảng Trị.

\section{Khái quát khu vực nghiên cứu}

Quảng Trị nằm trong phạm vi từ $16^{0} 18$ đến $17^{0} 10$ vĩ độ Bắc; $106^{0} 32$ đến $107^{0} 24$ kinh độ Đông. Phía Bắc giáp với tỉnh Quảng Bình, phía Nam giáp với tỉnh Thừa Thiên Huế, phía Tây giáp tỉnh Savanakhet và Salavan - nước CHDCND Lào, phía Đông là biển Đông với chiều dài bờ biển là $75 \mathrm{~km}[1]$.

Quảng Trị là một tỉnh nghèo miền Trung, dân số chủ yếu sống tập trung ở dải ven biển và dọc theo các hệ thống sông chính là sông Bến Hải và Thạch Hãn, vì thế các hoạt động dân

\footnotetext{
Tác giả liên hệ. ĐT.: 84-983250586

Email: anhtuan86bca@gmail.com
}

sinh kinh tế của người dân phụ thuộc rất lớn vào chế độ thủy văn cũng như chất lượng nước của các hệ thống sông này đặc biệt là các thành phần kinh tế nông nghiệp và nuôi trồng thủy sản (NTTS).

Cũng như một số tỉnh miền Trung khác, nuôi trồng thủy sản ở tỉnh Quảng Trị có xu hướng phát triển mạnh trong khoảng thời gian 10 năm trở lại đây. Tổng diện tích nuôi trồng thủy sản của Quảng Trị năm 2003 là 1730 ha, năm 2006 là 2380,4 ha và đến năm 2013 là hơn 3,1 nghìn ha $[2,4]$. Theo số liệu thống kê thu được của Sở Nông nghiệp và phát triển nông thôn tỉnh Quảng Trị, trong năm 2013 tính riêng diện tích nuôi trồng thủy sản nước ngọt là 2185 ha và nước mặn, nước lợ là 1022 ha [4]. 


\section{Vấn đề ô nhiễm do nuôi trồng thủy sản}

Bên cạnh các lợi ích kinh tế mà NTTS mang lại thì sự phát triển của lĩnh vực này cũng có những tác động tiêu cực đến môi trường trong và ngoài ao nuôi.

Đối với các ao hồ nuôi thủy sản nước ngọt, hình thức nuôi là bán thâm canh hoặc nuôi thả, nước thải ra chủ yếu trong các đợt thay nước nuôi và khi thu hoạch, được xả trực tiếp vào môi trường không qua xử lý. Các hộ nói chung không sử dụng các loại thuốc kháng sinh, tuy nhiên ô nhiễm vẫn xuất hiện do thức ăn thừa gây nên [1].

Đối với các khu nuôi nước mặn, lợ thì nước thải được xả thẳng ra môi trường với lưu lượng và tần suất lớn. Đối với tôm sú và tôm chân trắng, thời gian thay nước có thể lên tới $20 \%$ lượng nước nuôi trồng trong 1 ngày, mang theo thức ăn thừa và các chất thuốc kháng sinh, ảnh hưởng lớn đến môi trường xung quanh [1].

Thành phần lớp bùn trong các đầm, ao NTTS chủ yếu là các chất hữu cơ như prôtêin, lipids, axit béo, photpholipids, Sterol, vitamin $\mathrm{D} 3$, các hoocmon, carbohydrate, chất khoáng và vitamin, vỏ tôm lột xác,... Lớp bùn này luôn ở trong tình trạng ngập nước, yếm khí, các vi sinh vật yếm khí phát triển mạnh, phân huỷ các hợp chất trên tạo thành các sản phẩm là hydrosulphua $\left(\mathrm{H}_{2} \mathrm{~S}\right)$, a-mô-ni-ắc $\left(\mathrm{NH}_{3}\right)$, khí metan $\left(\mathrm{CH}_{4}\right), \ldots$ rất có hại cho thuỷ sinh vật. Khí a-mô-ni-ắc $\left(\mathrm{NH}_{3}\right)$ cũng được sinh ra từ quá trình phân huỷ yếm khí thức ăn tồn dư gây độc trực tiếp cho tôm, làm ảnh hưởng đến độ $\mathrm{pH}$ của nước và kìm hãm thực vật phù du phát triển [5].

Việc sử dụng các chất hóa học trong việc bảo vệ sức khoẻ động vật thuỷ sản đang diễn ra phổ biến. Ngành NTTS công nghiệp sử dụng một lượng lớn các loại thuốc kháng sinh và các loại thuốc khác và sự lạm dụng hoặc dùng không đúng cách thì tồn dư của chất hóa học này có thể kéo theo những hậu quả nhất định đến hệ sinh thái thủy sinh và nguồn nước tiếp nhận xung quanh $[3,5]$.

Quá trình chuyển dịch sử dụng đất từ các diện tích trồng lúa sang nuôi trồng thủy sản diễn ra quy mô lớn ở vùng mặn hóa ven biển làm gia tăng xâm nhập mặn ở các vùng ven biển. Nhiều ao hồ nuôi tại các khu đất ở sinh hoạt, hoặc các khu đất ven biển, ven sông, được lót đáy, nên nước nuôi không trực tiếp ngấm xuống đất. Tuy nhiên, khi xả thải không xử lý sẽ gây ảnh hưởng đến nguồn nước ngầm. Đồng thời, quá trình nuôi trồng đòi hỏi bổ sung một lượng lớn nước sạch, chủ yếu từ các giếng khoan dẫn đến khả năng làm sụt mực nước ngầm, sụt lở đất $[1,3]$.

Theo Cơ quan bảo vệ môi trường (Environemtal Protection Agency - EPA) của Hoa Kỳ - hoạt động nuôi trồng thủy sản phát sinh nhiều yếu tố có thể gây nguy hại đến môi trường thủy sinh nếu xả thải vào môi trường nước tiếp nhận một lượng đáng kể [6].

Chất rắn lơ lửng tăng làm tăng độ đục, gây cản trở sự xâm nhập của ánh mặt trời, qua đó làm giảm hoạt động quang hợp và tiêu thụ ô-xy của thực vật thủy sinh và phù du, lượng ô-xy hòa tan trong nước sẽ giảm và khiến động vật (tôm, cá,...) chết theo. Việc gia tăng chất lơ lửng còn khiến nhiệt độ nước bề mặt tăng cao do hấp thụ nhiều ánh mặt trời, cũng sẽ làm giảm lượng ô-xy hòa tan trong nước. Chất rắn lơ lửng làm xước xát mang và da của động vật thủy sinh nhạy cảm, tăng nguy cơ nhiễm trùng và bệnh tật. Khi lắng xuống đáy, các hạt rắn còn có thể làm hỏng trứng cá, gây cản trở cho sự sinh sản của các loài thủy sản.

Ni-tơ cùng với Phốt-pho là hai dưỡng chất chính trong các khu NTTS được xả thải ra môi trường. Việc các nguồn nước tiếp nhận dư thừa quá nhiều dưỡng chất sẽ dẫn đến hiện tượng phú dưỡng, gây hậu quả như là thực vật phát triển quá mức, đục nước, DO thấp, cá chết, suy giảm hệ sinh vật, kích thích hoạt động của vi sinh vật, trong đó có một số chủng loài có hại đến sức khỏe con người.

Chất hữu cơ được thải từ các khu NTTS chủ yếu do phân và thức ăn thừa. Nồng độ chất hữu cơ gia tăng sẽ làm tăng nhanh hiện tượng phú dưỡng và suy giảm ô-xy (vi sinh vật cần tiêu thụ ô-xy để phân hủy chất hữu cơ).

Sự gia tăng về diện tích NTTS nước mặn, lợ dẫn tới sự gia tăng tải lượng các chất hữu cơ và 
cặn lơ lửng. Tuy nhiên do khả năng tự làm sạch hiện thời của hai con sông là lớn nên chưa gây ra hậu quả nghiêm trọng. Tuy nhiên, nồng độ chất ô nhiễm hữu cơ và cặn lơ lửng đặc biệt lớn tại các vị trí xả thải của các ao nuôi và trong thời gian các ao nuôi xả thay nước.

\section{3. Ứng dụng mô hình MIKE 11 mô phỏng quá trình lan truyền chất ô nhiễm và tự làm sạch}

Để đánh giá tình hình ô nhiễm chất lượng nước trên các hệ thống sông tỉnh Quảng Trị, phương pháp được sử dụng là phương pháp mô hình tính thủy động lực kết hợp với lan truyền chất và quá trình biến đổi sinh học của các hợp chất trong sông. Nhóm nghiên cứu đã lựa chọn bộ mô hình MIKE 11 với các mô đun thủy động lực $(\mathrm{HD})$, mô đun lan truyền chất $(\mathrm{AD})$ và mô đun chất lượng nước (WQ).

\subsection{Lý thuyết mô hình MIKE 11 [7,8]}

Mô đun thủy lực (HD): được xây dựng trên cơ sở hệ phương trình Saint Venant bao gồm hai phương trình, để xác định lưu lượng và mực nước tại các mặt cắt trên hệ thống sông, đây chính là cơ sở để xây dựng hầu hết các mô đun khác.

Mô đun lan truyền chất $(A D)$ : được dùng để mô phỏng vận chuyển một chiều của chất huyền phù hoặc phân hủy trong các lòng dẫn hở dựa trên phương trình khuếch tán.

Mô đun chất lượng nước (WQ): giải quyết khía cạnh chất lượng nước trong sông. Mô đun này luôn đi kèm với mô đun lan truyền chất, có nghĩa là mô đun chất lượng nước giải quyết các quá trình biến đổi sinh học của các hợp chất trong sông còn mô đun lan truyền chất được dùng để mô phỏng quá trình tải khuếch tán của các hợp chất đó.

\subsection{Thiết lập mang thủy lực}

Khu vực nghiên cứu có hai hệ thống sông chính là Bến Hải và Thạch Hãn. Nối kết giữa hai hệ thống sông này là sông Cánh Hòm. Ngoài ra, trên địa bàn tỉnh Quảng Trị còn có sông Vĩnh Định, nối từ cống Việt Yên thuộc xã Triệu An chảy qua các huyện Triệu Phong, Hải
Lăng rồi nhập với hệ thống sông Ô Lâu trước khi đổ ra biền. Sơ đồ thủy lực mô phỏng phần hạ lưu được tính toán của các sông này được minh họa trên Hình 1.

\subsection{Số liệu}

Toàn bộ mạng tính toán 1 chiều được thiết lập với 140 mặt cắt, 398 nút tính toán. Để mô phỏng thủy lực cho hệ thống sông Bến Hải Thạch Hãn, số liệu lưu lượng tại 6 biên trên và số liệu mực nước tại 3 biên dưới được sử dụng bao gồm:

Số liệu biên trên: Cầu Sa Lung, Gia Vòng, Cam Tuyền, Đăkrông, Hải Sơn, Phò Trạch. Căn cứ trên điều kiện số liệu quan trắc, trong số các biên trên duy nhất có biên Gia Vòng lấy giá trị thực đo lưu lượng, các biên còn lại sử dụng tài liệu dòng chảy tính toán từ mưa bằng mô hình thủy văn (NAM) với bộ thông số đã được hiệu chỉnh và kiểm định.

Số liệu biên dưới: Mực nước triều tại Cửa Tùng, Cửa Việt, Cửa Lác. Mực nước triều tại Cửa Việt, Cửa Lác không có trạm đo, hiệu chỉnh theo mực nước tại Cửa Việt.

Các số liệu chất lượng nước được đưa vào tính toán mô phỏng trong nghiên cứu bao gồm DO, BOD, Tổng N. Nguồn số liệu đo đạc chất lượng nước trên sông hệ thống sông Bến Hải Thạch Hãn 10/2014 của Sở Tài nguyên và Môi trường tỉnh Quảng Trị được sử dụng để mô phỏng nền chất lượng nước.

Nguồn gây ô nhiễm xét đến trong nghiên cứu là các cơ sở nuôi trồng thủy sản trên địa bàn tỉnh. Dựa trên các đợt khảo sát, vị trí xả thải, lưu lượng xả và nồng độ tại các vị trí xả đã được thu thập. Điểm xả thải của một số khu được tập hợp thành các kênh xả đổ vào hệ thống sông chính. Tải lượng các chất ô nhiễm gia nhập từ các kênh xả đó được đưa vào mô hình như là các biên nội của hệ thống.

\subsection{Hiệu chỉnh và kiểm nghiệm mô hình thủy lực}

- Số liệu mực nước thực đo dùng để hiệu chỉnh mô hình: 17/9 - 5/12/2004. 
- Số liệu mực nước thực đo dùng để kiểm định mô hình: 1/9 - 30/11/2009 (Hình 2, 3).

Kết quả so sánh trên hình $2-3$ cho thấy giá trị tính toán từ mô hình phù hợp với giá trị thực đo cả về giá trị và pha dao động. Đường quá trình mực nước gần như trùng khít. Từ kết quả này cho thấy có thể ứng dụng mô hình cho các tính toán tiếp theo.

\subsection{Thiết lập mô hình chất lượng nuơơc}

Điều kiện ban đầu: dựa vào các số liệu quan trắc môi trường tại các vị trí trên các sông tỉnh Quảng Trị năm 2014 để thiết lập các điều kiện khởi tạo ban đầu của hệ thống và hệ số khuếch tán $\mathrm{D}\left(\mathrm{m}^{2} / \mathrm{s}\right)$.

Biên lưu lượng nhập bên: gồm 12 biên nhập bên, lưu lượng thải từ các nguồn gây ô nhiễm. Biên nồng độ: nồng độ các chất tại biên trên, biên dưới và biên nhập bên Mô hình đã chạy với thời gian từ $1 / 10-31 / 10$. Hình $9,10,11$ là các bản đồ mô phỏng nồng độ các chất ô nhiễm cao nhất trên hệ thống sông thuộc tỉnh Quảng Trị (Hình 4, 5, 6).

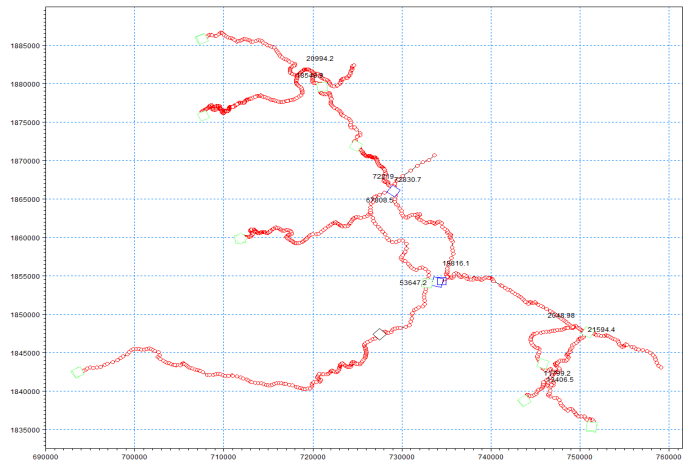

Hình 1. Sơ đồ mạng lưới tính toán thủy lực hệ thống sông Bến Hải - Thạch Hãn.

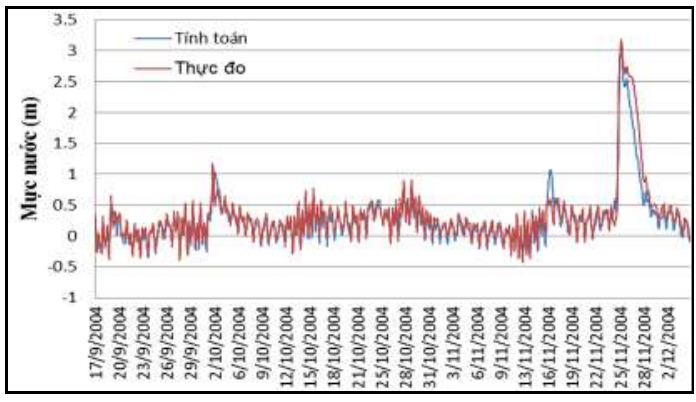

Hiệu chỉnh

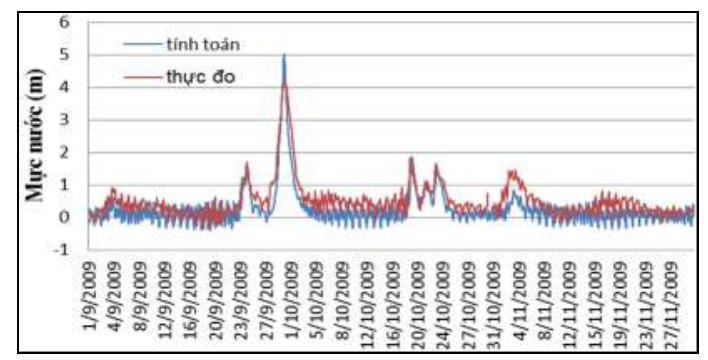

Kiểm Định

Hình 2. Kết quả hiệu chỉnh và kiểm định mô hình thủy lực tại trạm Đông Hà.

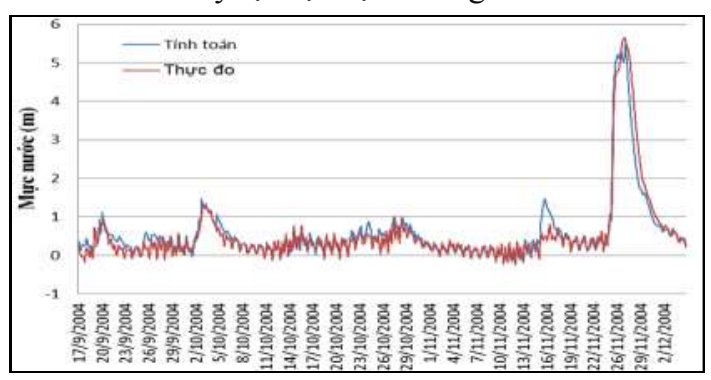

Hiệu chỉnh

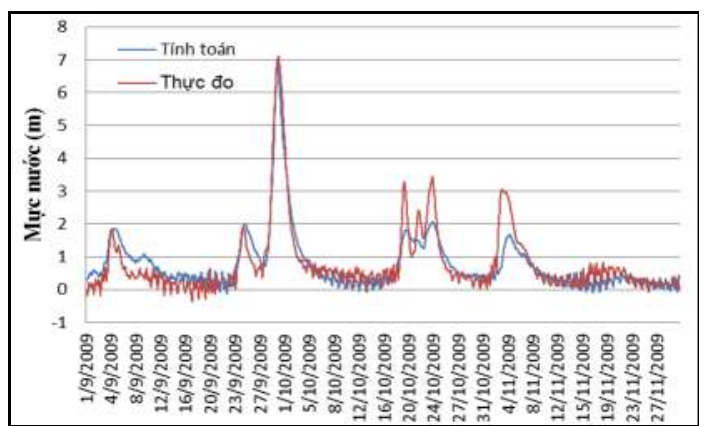

Kiểm định

Hình 3. Kết quả hiệu chỉnh và kiểm định mô hình thủy lực tại trạm Thạch Hãn.

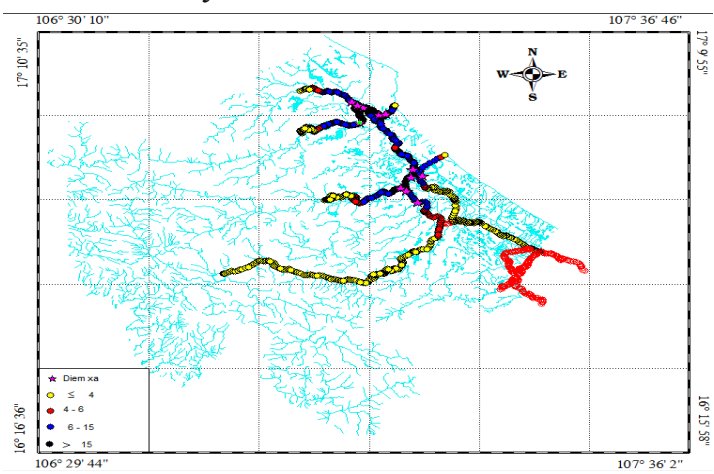

Hình 4. Bản đồ phân bố nồng độ BOD trên hệ thống sông tỉnh Quảng Trị. 


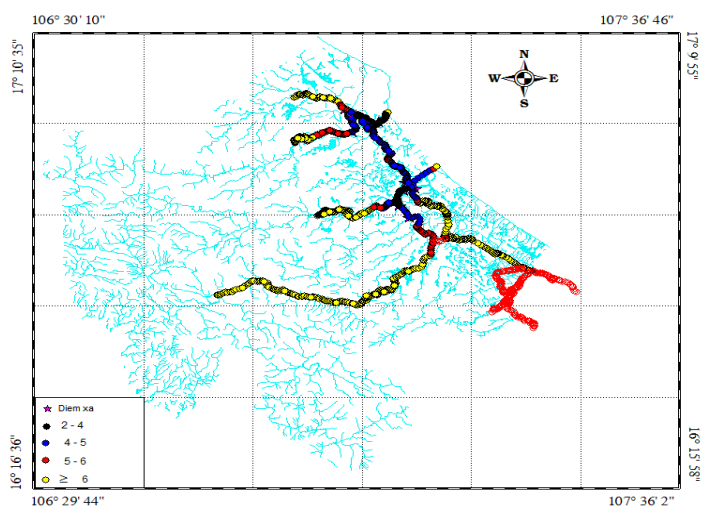

Hình 5. Bản đồ phân bố nồng độ DO trên hệ thống sông tỉnh Quảng Trị.

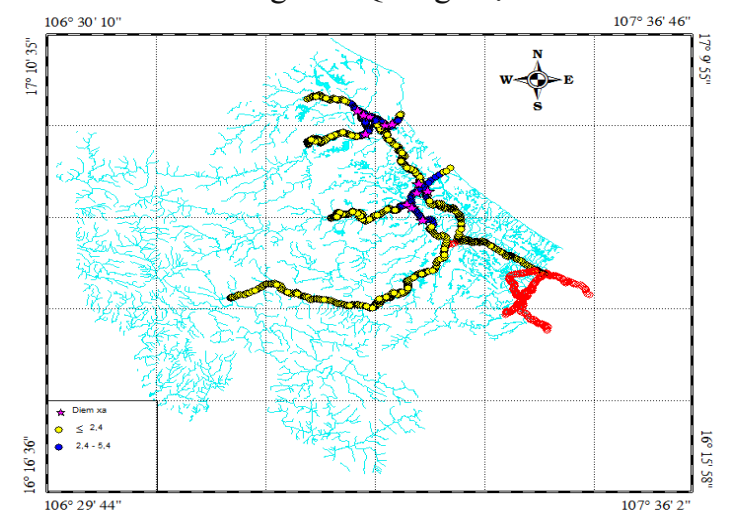

Hình 6. Bản đồ phân bố nồng độ tổng $\mathrm{N}$ trên hệ thống sông tỉnh Quảng Trị.

\section{Kết luận}

Các kết quả mô phỏng cho thấy mô hình Mike 11 đã đáp ứng khá tốt việc tính toán mô phỏng thủy văn, thủy lực và chất lượng nước trên các sông thuộc địa bàn tỉnh Quảng Trị. Việc ứng dụng chạy mô phỏng cho một thời gian dài liên tục 30 ngày giúp mô hình có tính ổn định cao, mô phỏng được đầy đủ các quá trình lan truyền chất và tự làm sạch trên sông.

Từ các bản đồ trên cho thấy, hầu hết nồng độ $\mathrm{BOD}, \mathrm{DO}, \mathrm{N}$ đều nằm trong giới hạn $\mathrm{A} 1$. Tuy nhiên, nồng độ $\mathrm{BOD}, \mathrm{DO}$ tại các vị trí ao nuôi và khu vực xung quanh các ao nuôi có xu hướng tăng dần và vượt mức giới hạn $\mathrm{B} 1$. Giá trị nồng độ tổng $\mathrm{N}$ cũng tăng dần tại các vị trí ao nuôi, nhưng đều nằm trong giới hạn $\mathrm{A} 1, \mathrm{~A} 2$.

Kết quả trên mô hình cho thấy, tại các điểm xả, môi khi nước thải NTTS được xả ra trong thời gian khoảng 1-2 tiếng thì lượng chất ô nhiễm sẽ trôi xa khoảng $11 \mathrm{~km}$ trên sông Bến Hải, $5 \mathrm{~km}$ trên hệ thống sông Thạch Hãn, 3,5 $\mathrm{km}$ trên sông Sa Lung. Thời gian để quá trình tự làm sạch và pha loãng xáo trộn đưa chất lượng nước về các giá trị cân bằng ban đầu là khoảng một đến vài ngày, tùy thuộc vào các điểm xả thải (có các giá trị nồng độ và lưu lượng xả thải khác nhau).

Nghiên cứu sử dụng các số liệu đo đạc trong năm 2014, tuy nhiên với sự thay đổi nhanh chóng diện tích nuôi trồng thủy sản, chất lượng nước trong các sông cũng sẽ thay đổi rất nhanh theo chiều hướng xấu. Vì thế, sử dụng mô hình kết hợp với các số liệu đo đạc mới nhất có thể là một công cụ tốt để quy hoạch nuôi trồng thủy sản cho các địa phương trên tỉnh, dựa vào kết quả tính toán tải lượng ô nhiễm tối đa trên sông.

\section{Tài liệu tham khảo}

[1] Nguyễn Quang Hưng, Nguyễn Thanh Sơn, Nguyễn Vũ Anh Tuấn (2015), "Tổng quan các phương pháp xử lý có khả năng áp dụng để xử lý nước thải nuôi trồng thủy sản tại tỉnh Quảng Trị”, Tạp chí Khoa học ĐHQGHN: Khoa học Tự nhiên và Công nghệ, Tập 31, Số 1S, tr. 39 - 47.

[2] Nguyễn Tiền Giang và mk (2007), Đánh giá hiện trạng ô nhiễm nguồn nước do nuôi trồng thủy sản, vấn đề xâm nhập mặn tỉnh Quảng Trị và đề xuất các giải pháp góp phần phát triển kinh tế xã hội và bảo vệ môi trường.

[3] Nguyễn Tiền Giang, Trần Ngọc Anh, Nguyễn Thanh Sơn và mk (2007), Đánh giá hiện trạng ô nhiễm nguồn nước do nuôi trồng thủy sản, vấn đề xâm nhập mặn tỉnh Quảng Trị và đề xuất các giải pháp góp phần phát triển kinh tế xã hội và bảo vệ môi trường, Trường Đại học Quốc gia Hà Nội.

[4] Sở nông nghiệp và phát triển nông thôn tỉnh Quảng Trị (2013), Báo cáo tình hình nuôi trồng thủy sản 2013. Kế hoạch nuôi trồng thủy sản năm 2014, Quảng Trị.

[5] Trịnh Ngọc Tuấn (2005), Nghiên cứu hiện trạng khai thác, nuôi trồng thủy sản ở Việt Nam và đề xuất phương pháp xử lý nước thải.

[6] Environmental Protection Agency (2004), "Chapter 6: Water use, wastewater characterization, and pollutants of concern". 
Technical development document for the final effluent limitations guidelines and new source performance standards for the concentrated aquatic animal production point source category (Revised August 2004).
[7] Denmark Hydraulic Institute (DHI), MIKE 11 User Guide, DHI, 2004

[8] Denmark Hydraulic Institute (DHI), Reference Manual, MIKE 11 - A modeling system for rivers and channels, DHI, 2004.

\title{
Application of MIKE 11 Model to Simulate the Spread of Contaminants caused by Aquaculture Acitivities on Some Major Rivers in Quang Tri Province
}

\author{
Nguyen $\mathrm{Vu}$ Anh Tuan ${ }^{1}$, Nguyen Thanh Son ${ }^{2}$, \\ Nguyen Quang ${ }^{2}$, Nguyen Thi Lien ${ }^{2}$ \\ ${ }^{I}$ Department of Logistic and Engineering, Ministry of Public Security, \\ 80 Tran Quoc Hoan Street, Cau Giay, Hanoi, Vietnam \\ ${ }^{2}$ VNU University of Science, 334 Nguyen, Thanh Xuan, Hanoi, Vietnam
}

\begin{abstract}
By means of using MIKE 11 Model with the consideration to the impact of the discharge from aquaculture sites, this paper show the simulation results on water quality of some major rivers in Quang Tri Province. The rainfall and water level data in the year of 2005 and 2009 were used to run hydrology and hydraulic models. In addition, the monitoring data of water quality at more than 30 points as well as the measured data at the aquaculture ponds, which were taken in the year of 2013 and 2014, were used to establish water quality model and simulate the spread of contaminants on rivers. The simulation results were compared with the measured data in order to confirm the reliability of the modelling process. Some analysis were conducted in order for demostrating current state of water quality as well as making fundament to research and create an aquaculture plan in terms of environmental protection in Quang Tri Province.
\end{abstract}

Keywords: Water quality, Aquaculture, MIKE 11, Quang Tri. 